\title{
Transcriptomic and proteomic analyses reveal new insights into the regulation of immune pathways during adenovirus type 2 infection
}

Hongxing Zhao ${ }^{1 *}$ (D) Maoshan Chen ${ }^{2}$, Alberto Valdés ${ }^{3}$, Sara Bergström Lind ${ }^{4}$ and Ulf Pettersson ${ }^{1}$

\begin{abstract}
Background: Human adenovirus (Ad) infection leads to the changes of host cell gene expression and biosynthetic processes. Transcriptomics in adenovirus type 2 (Ad2)-infected lung fibroblasts (IMR-90) cells has previously been studied using RNA sequencing. However, this study included only two time points (12 and $24 \mathrm{hpi}$ ) using constrained $76 \mathrm{bp}$ long sequencing reads. Therefore, a more detailed study of transcription at different phases of infection using an up-graded sequencing technique is recalled. Furthermore, the correlation between transcription and protein expression needs to be addressed.

Results: In total, 3556 unique cellular genes were identified as differentially expressed at the transcriptional level with more than 2-fold changes in Ad2-infected cells as compared to non-infected cells by using paired-end sequencing. Based on the kinetics of the gene expression changes at different times after infection, these RNAs fell into 20 clusters. Among them, cellular genes involved in immune response were highly up-regulated in the early phase before becoming down-regulated in the late phase. Comparison of differentially expressed genes at transcriptional and posttranscriptional levels revealed low correlation. Particularly genes involved in cellular immune pathways showed a negative correlation. Here, we highlight the genes which expose inconsistent expression profiles with an emphasis on key factors in cellular immune pathways including NFKB, JAK/STAT, caspases and MAVS. Different from their transcriptional profiles with up- and down-regulation in the early and late phase, respectively, these proteins were up-regulated in the early phase and were sustained in the late phase. A surprising finding was that the target genes of the sustained activators failed to show response.

Conclusion: There were features common to genes which play important roles in cellular immune pathways. Their expression was stimulated at both RNA and protein levels during the early phase. In the late phase however, their transcription was suppressed while protein levels remained stable. These results indicate that Ad2 and the host cell use different strategies to regulate cellular immune pathways. A control mechanism at the post-translational level must thus exist which is under the control of $\mathrm{Ad} 2$.
\end{abstract}

\footnotetext{
* Correspondence: Hongxing.Zhao@igp.uu.se

'The Beijer laboratory, Department of Immunology, Genetics and Pathology,

Uppsala University, S-751 85 Uppsala, Sweden

Full list of author information is available at the end of the article
}

(c) The Author(s). 2019 Open Access This article is distributed under the terms of the Creative Commons Attribution 4.0 International License (http://creativecommons.org/licenses/by/4.0/), which permits unrestricted use, distribution, and reproduction in any medium, provided you give appropriate credit to the original author(s) and the source, provide a link to the Creative Commons license, and indicate if changes were made. The Creative Commons Public Domain Dedication waiver (http://creativecommons.org/publicdomain/zero/1.0/) applies to the data made available in this article, unless otherwise stated. 


\section{Introduction}

Change of host cell gene expression and biosynthetic processes during a human adenovirus infection is a stepwise, but efficient mode of turning host antiviral responses to facilitate the replication of adenovirus. Most interactions between host cell and virus take place during the early phase. Adenovirus-mediated regulation of cellular gene expression emphasizes two major aspects: induction of its host cell to enter S-phase of the cell cycle and interference with host defense mechanisms. It has been shown that host cells are reprogrammed epigenetically as a result of adenovirus early-region function at different times after infection [1]. Adenovirus expresses several regulatory proteins from early regions $1 \mathrm{~A}$ (E1A), E1B, E3, and E4. E1A is the first viral gene expressed and plays essential roles in regulation of viral and cellular gene expression [2]. E1A does not bind DNA directly by itself, but by binding to many important transcriptional regulators, E1A regulates the expression of important genes that control the cell cycle and cellular innate antiviral response [3-10]. The interaction of E1A with the retinoblastoma tumor suppressor (pRB) family proteins results in disassembling of a series of inhibitory complexes between $\mathrm{pRB}$ and the transcription factor E2F family, leading to the activation of E2F family of transcription factors. As consequence, the E2F-dependent S-phase genes are expressed [6, 7]. The interaction of E1A with the coactivators p300/CBP disrupts the histone acetyltransferase activity of p300/CBP and their associated factor PCAF, leading to decreased transcription from a variety of different genes involved in growth arrest, cell differentiation and immune evasion [4, 5, 8, 9, 11-14]. Furthermore, E1A proteins interfere with host immune response by blocking type I IFN-inducible gene expression [15]. E1A protein directly antagonizes a cellular histone posttranslational modification mediated by hBre1/RNF20, thus inactive the cellular IFN-stimulated gene (ISG) expression [16]. E1A associates with hypophosphorylated pRB1 and p300/CBP and translocate the complex to the gene bodies of repressed genes [17]. Many components of TGF $\beta$-, TNF-, and interleukin-signaling pathways are among their targets. A recent study shows that the E1A C terminus interacts with three cellular proteins FOXK, DCAF7 and CtBP and suppress activation of a subset of ISGs [18]. In addition, it has been shown that E1A protein prevents the peptide presentation to the immunoproteosome by interacting with MECL1 [19].

E1B encodes two major proteins, the E1B-55 $\mathrm{K}$ and E1B-19 K proteins. E1B- $55 \mathrm{~K}$ is a multi-functional protein and plays a major role in counteracting the cellular proapoptotic program. Association of E1B-55 k and E4-orf6 proteins with several cellular proteins, Cullin 5, TCEBs and RBX1 forms a virus-specific E3 ubiquitin ligase which then targets specific cellular proteins for degradation [20, 21].
The E1B-55 K protein serves as the substrate-recognition subunit via distinct sequences and targets the p53 protein, thereby promoting degradation of p53 [21, 22]. The E1B-19 K protein, a viral Bcl-2 homologue, interferes directly with the activity of p53 when translocated into the mitochondria [23-25]. Proteins generated from the E3 region also play a very important role in countering host antiviral defenses [26]. E3-gp19K prevents the exposure of viral peptides on the cell surface by blocking the transport of the class I major histocompatibility complex (MHC I) molecule to the cell surface and the loading of peptides by tapasin [27-29]. The E3-10.4 K and 14.5 K (RID $\alpha / \beta)$ complex inhibits tumor necrosis factor alpha (TNF $\alpha)$ and Fas ligand-induced apoptosis through internalization and degradation of the death domain containing receptors [30]. In addition, the E3-10.4 K/14.5 K complex blocks the activation of $\mathrm{NF \kappa B}$ by preventing it from entering the nucleus and inhibiting the activity of the kinase complex IKK [31]. Proteins encoded by the E4 region are involved in transcriptional regulation. E4-orf6/7 stabilizes the binding of E2F to the duplicated E2F binding sites in the E2 promoter [32, 33]. E4-orf3 associates with $\mathrm{E} 1 \mathrm{~B}-55 \mathrm{~K}$ in the nuclear promyelocytic leukemia protein oncogenic domains (POD) and reorganizes PODs during infection, thus likely involved in the regulation of transcription factor availability and activity [34, 35]. The E4-orf4 protein interacts with protein phosphatase $2 \mathrm{~A}$, leading to the inhibition of E1A-dependent transactivation of the JunB promoter [36-38].

When adenovirus DNA replication commences, the infection cycle proceeds into the late phase. Viral transcription changes from the early to the late pattern. The L4-100 kDa protein, expressed from the major late transcription unit is necessary for efficient initiation of viral late mRNA translation [39-41]. Furthermore, the E1B-55 kDa and E4-orf4 protein complex is involved in regulation of mRNA export from nucleus, resulting in a block of cellular mRNAs export and selective export of viral mRNAs [42, 43]. As a consequence, a dramatic down-regulation of cellular gene expression occurs late in infection [44].

Most studies of the adenovirus infection have been performed in Hela cells, in which adenovirus replication is very efficient and the infectious cycle is completed after 20-24h [45]. Particularly, the early phase is very short, lasting for less than $6 \mathrm{~h}$. Thus, there is a narrow time window for a detailed examination of the changes of cellular gene expression. Furthermore, being transformed cells, Hela cells grow rapidly and are difficult to synchronize. Thus, genes involved in the control of cell cycle and growth might escape detection. Therefore, human primary cells, like human lung fibroblasts (IMR-90) or foreskin cells (HFFs) have been used for a series of studies [44, 46-49]. In these cells adenovirus DNA 
replication starts $24 \mathrm{~h}$ post infection (hpi). Based on cellular transcription profiles from early cDNA microarray study, Ad2 infection of IMR-90 cells can be divided into four periods [44]. The first period (1-12 hpi) extends from the attachment of Ad2 to the cell surface to the beginning of adenoviral early gene expression. During this time, the cellular gene expression changes are mainly triggered by the virus entry process. The majority of the genes deregulated during the first phase have functions linked to cell growth and immune response. The second period covers the time from the expression of the immediate early E1A gene to the time when Ad2 DNA replication starts $(12-24 \mathrm{hpi})$. During this period, there is a linear increase in the number of differentially expressed cellular genes involved primarily in cell cycle regulation and cell proliferation. The third period ranges from the beginning of DNA replication to the time when the cytopathic effect (CPE) starts (24-36 hpi). By this time, the virus has gained control of the cellular metabolic machinery, resulting in an efficient replication of the viral genome and expression of the capsid proteins. Additional changes in cellular gene expression are modest during this phase. The final period starts when CPE is apparent (after $36 \mathrm{hpi}$ ). The number of down-regulated genes increases dramatically and includes many genes involved in intra- and extracellular structure, leading to an efficient burst of progeny.

The rapid development of high throughput sequencing technology enabled the exploration of the transcriptome on a genome-wide scale at single base pair resolution. Meanwhile, several proteomics approaches have been applied. Improve shotgun/bottom-up liquid chromatography-tandem mass spectrometry (LC-MS/MS)-based protein detection and quantitative techniques such as Stable Isotope Labelling of Amino acids in Cell culture (SILAC) have greatly facilitated protein identification $[50,51]$. These technologies have been used in studies of protein expression in adenovirus-infected cells. Lam et al. have analyzed the nucleolar proteome in Ad5-infected Hela cells [52], while Evans et al. have examined the posttranscriptional stability of cellular protein in Ad5-infected Hela cells [53]. Recently, a comparative proteome analysis of wild type and E1B-55 K-deleted viruses was performed to investigate the role of Ad5 E1B-55 K in targeting cellular proteins with antiviral activity for proteasomal degradation [54]. Previously, we have presented a general comparison of the cellular transcriptome and proteome of Ad2-infected IMR-90 cell at 24 and 36 hpi [48]. More than 700 proteins were identified to be differentially expressed. Surprisingly, there was a very low correlation between the RNA and protein expression profiles. Here, we present a more comprehensive study of the cellular transcription profiles at four critical stages of an adenovirus infection in IMR-90 cells using paired-end sequencing. As a step further, RNA expression profiles were compared with protein expression profiles with a focus on genes involved in the cellular immune response.

\section{Materials and methods \\ Cell culture and virus infection}

Human lung fibroblast IMR-90 cells (American Type Culture Collection, ATCC) were initially cultured in Eagle's minimum essential medium (EMEM) (ATCC) supplemented with $10 \%$ fetal bovine serum (FCS), $100 \mathrm{U} / \mathrm{ml}$ penicillin and $100 \mu \mathrm{g} / \mathrm{ml}$ streptomycin at $37^{\circ} \mathrm{C}$ and $5 \%$ $\mathrm{CO}_{2}$. After reaching conluent, cells were maintained in the plates for two days before infection. By fluorescence-activated cell sorting (FACS) analysis, more than $95 \%$ of the cells were characterized in G0/G1 phase. Synchronized cells were then infected with human adenovirus type 2 at a multiplicity of infection (MOI) of 10. Mock-infected cells were used as a control. One hour later, the medium was replaced with complete EMEM medium supplemented with $10 \%$ FBS. Infected cells were collected at $6,12,24$, and $36 \mathrm{~h}$ post infection (hpi).

\section{Total RNA extraction, RNA library construction and sequencing}

Total RNA from infected IMR-90 cells were extracted with TRIzol ${ }^{\circ}$ (Invitrogen), according to the manufacturer's instructions. The quality of total RNA was evaluated with a NanoDrop 1000 spectrophotometer and an Agilent 2100 Bioanalyzer. After treatment with Ribo-Zero $^{\mathrm{m}}{ }^{\mathrm{r}}$ rRNA removal reagent, total RNA was used to construct cDNA library for transcriptome sequencing following the ScriptSeq ${ }^{\text {Tw }}$ v2 RNA-Seq library preparation kit according to the manufacturer's protocol (Epicentre). The cDNA libraries were sequenced on a HiSeq 2000 sequencing platform (Illumina).

\section{Genome alignment and gene expression profile}

Data cleaning was performed by removing low quality, contaminant and adapter reads from the raw reads. TopHat2 and Cufflinks were used to align the filtered reads to human Ensembl genome (http://www.ensembl.org/index.html, GRCh38) and to profile gene expression following the protocol [55], respectively. FPKM (fragments per kilobase per million reads mapped) method was employed to normalize gene expression. To strengthen the reliability of our results, lowly expressed genes $(<10$ FPKM in all libraries) were filtered out.

\section{Identification of differentially expressed genes in Ad2- infected cells}

To identify genes deregulated in early and late phases of Ad2 infection, we performed correlation analysis between samples based on normalized gene expression values 
using the CORREL function provided by Excel. To identify differentially expressed genes in the cells infected by Ad2, several statistical values were used. First, a fold change of a particular gene in Ad2-infected cells was calculated following the rule: fold change $(\operatorname{Ad} 2$-infected $/$ mock $)=y / x$, while $\mathrm{y}$ and $\mathrm{x}$ represent the normalized expression values in Ad2-infected and mock cells, respectively. A cut-off of more than 2-fold increase or decrease was used. Second, a $p$-value that represents the significance for differential expression was calculated based on Poison distribution [56]. A cut-off for $p$-values $(<0.05)$ was used for differentially expressed genes. Last, an R package called NOISeq was used to calculate the probability of differential expression of a gene in a comparison [57]. Only those genes with probability $>0.7$ were kept for further analysis.

\section{Gene ontology and KEGG pathway enrichment}

To determine the biological processes and KEGG pathways affected by human adenovirus type 2, differentially expressed genes were analyzed by DAVID Bioinformatics Resources 6.7 (http://david.abcc.ncifcrf.gov/) [58].

\section{SILAC-MS experiment and protein identification}

The protein labelling were performed as described before [48]. Briefly, after growing in cell culture medium containing with heavy or light amino acids for at least six passages, cells were mock infected or infected with Ad2 at MOI of 10 in serum-free medium [59]. A biological replicate with swapped labeling was also performed. After harvest, cells were lysed and mock- and Ad2-infected lysates of different labeling were combined in a 1:1 protein ratio. Proteins were fractionated using SDS-PAGE. Following in-gel tryptic digestion [60], peptides were extracted and analyzed using nano liquid chromatography coupled on-line to a QExactive Orbitrap Plus Mass spectrometer (ThermoFisher Scientific, Bremen,Germany). Acquired data (raw-files) were imported into MaxQuant software (version:1.4.5.7) [61], and searched against a FASTA-file containing both cellular and Ad2 proteins downloaded from UniProt 2017-02. The ratio of the chromatographic areas of heavy and light peptides matching to specific proteins was used for determining the protein expression levels.

\section{Results \\ Host cell transcriptional profiles during the course of an adenovirus infection}

Regulation of cellular transcription during Ad2 infection was studied using paired-end sequencing technology. Four infection time points, 6, 12, 24 and $36 \mathrm{~h}$ post infection (hpi), were chosen which represent different stages of Ad2 infection. Besides, all of our early studies on expression of cellular various RNAs including micro RNA (miRNA), long non-coding (lncRNA) and protein were performed under the same condition [44, 46, 47]. Thus, we could compare the various expression profiles. About 30 million $255 \mathrm{bp}$ long sequence reads per sample were generated and $53-58 \%$ of them accounted for mRNA. From them 6860 cellular genes were identified to be transcribed at a significant level with a minimum of 10 FPKM (fragments per kilobase per million reads mapped) (Table 1). Among them, expressions of 3556 genes were changed more than or equal to 2-fold with $p$-values $<0.05$ in infected cells as compared to non-infected cells. Very limited changes in RNA expression occurs during the early phases. Only 74 and 223 genes showed significant differential expression at 6 and $12 \mathrm{hpi}$, respectively. Most expression changes took place at $24 \mathrm{hpi}$ when infection proceeded into the late phase, 2239 and 3060 genes were differentially expressed at 24 and $36 \mathrm{hpi}$, respectively. Fewer differentially expressed genes were detected in this study as compared to our earlier study, in which 1267 and 3683 cellular genes were identified as differentially expressed at 12 and 24 hpi. However, the former study was less stringent and included genes covered with only one or more reads [62].

Based on the kinetics of change in gene expression at different stages of infection, 3451 out of 3556 genes fell into 20 major different expression clusters (Fig. 1). The complete list of genes in each cluster is included in Additional file 1: Table S1. At $6 \mathrm{hpi}$, more than $87 \%$ of the differentially expressed genes were up-regulated

Table 1 In total 12,927 cellular mRNAs were detected in five time points together. Among them 9738 mRNAs were common between all-time points. Expression of 6860 mRNAs reached to a significant level with a minimum of 10 FPKM. Among them 3556 mRNAs were upor down-regulated $\geq 2$-fold in Ad2-infected cells as compared to non-infected cells. Numbers of mRNAs at each time point are listed here

\begin{tabular}{llllll}
\hline Selection & Mock & Ad2-6 hpi & Ad2-12 hpi & Ad2-24 hpi & Ad2-36 hpi \\
\hline$\geq 1$ FPKM & 11,064 & 11,163 & 11,837 & 11,426 & 11,191 \\
$\geq 10$ FPKM & 5001 & 4846 & 5184 & 4692 & 4371 \\
$\geq$ 2-Fold change & & $74^{\mathrm{a}}$ & 223 & 2239 & 3060 \\
Up-regulated & $65^{\mathrm{b}}$ & 138 & 1694 & 2142 \\
Down-regulated & $9^{\mathrm{c}}$ & 85 & 545 & 918 \\
\hline
\end{tabular}

${ }^{a}$ Number of genes expression with more than 2-fold changes in Ad2-infected as compared to uninfected cells as measured by sequence reads. ${ }^{b}$ Number of more than 2-fold up-regulated mRNAs in Ad2-infected as compared to non-infected cells. 'Number of more than 2-fold down-regulated mRNAs in Ad2-infected as compared to non-infected cells 


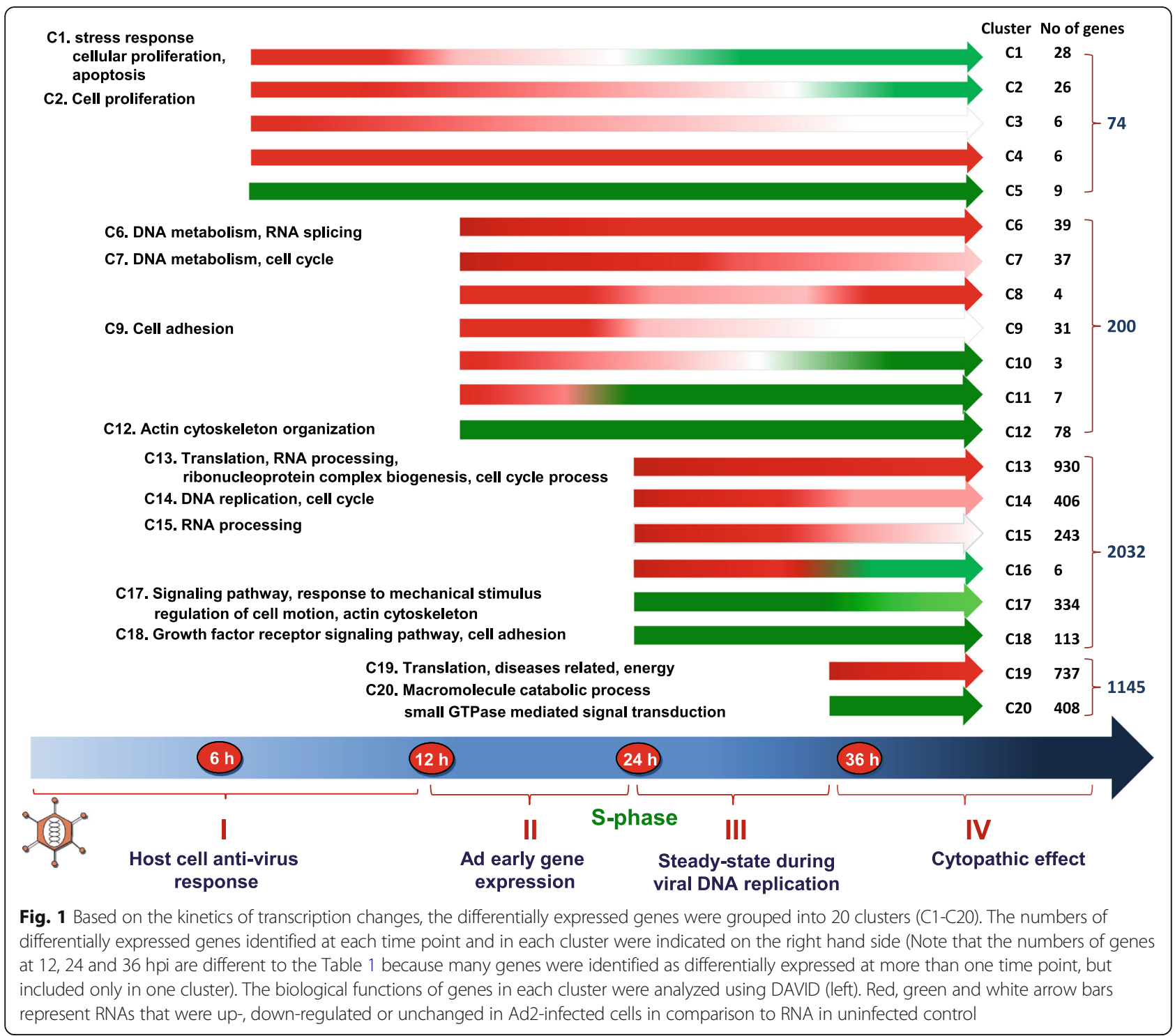

(Clusters $1+2+3+4)$. Expression of all of these genes reached their highest levels at $6 \mathrm{hpi}$, except two which reached their highest levels at $12 \mathrm{hpi}$. Then about $80 \%$ of them became down-regulated during the late phase of infection (Clusters 1 and Cluster 2). The rest either remained up-regulated (Cluster 4), or were gradually reduced to the basal level in the late phase (Cluster 3). Only 9 genes (Cluster 5) were down-regulated at $6 \mathrm{hpi}$ and their expression remained suppressed until the late phase.

At 12 hpi, 122 and 78 genes became up- and down-regulated in addition to the differentially expressed genes since 6 hpi. Among the up-regulated genes, about $1 / 3$ increased until 36 hpi (Cluster 6), 1/3 remained at a similar level through the rest of the infection (Cluster 7), and the remaining $1 / 3$ was only transiently up-regulated at 12 hpi (Cluster 9) and became down-regulated at $24 \mathrm{hpi}$ (Cluster 11) or at $36 \mathrm{hpi}$ (Cluster 10). Except one gene, all down-regulated genes at 12 hpi remained suppressed until the late phase (Cluster 12).

The most dramatic changes in gene expression took place between 12 to $24 \mathrm{hpi}$ then the infection proceeded from the early to the late phase. Thus, expression of 1585 and 447 (2032 in total) additional genes was upand down-regulated at $24 \mathrm{hpi}$. Based on the expression changes at $36 \mathrm{hpi}$, the up-regulated genes at $24 \mathrm{hpi}$ fell into four profiles (Cluster $13+14+15+16$ ). Expression of $59 \%$ of these genes increased until 36 hpi (Cluster 13), whereas $25 \%$ decreased but remained $>2$-fold higher than in non-infected cells (Cluster 14) and 15\% declined to less than 2 -fold changes at 36 hpi (Cluster 15). Only 6 genes became down-regulated at $36 \mathrm{hpi}$ (Cluster 16). Among 447 down-regulated genes, $75 \%$ decreased continually until 36 hpi (Cluster 17), while 25\% remained at a similar level (Cluster 18). Change in cellular gene expression was 
modest between 24 to $36 \mathrm{hpi}$ as compared to that between 12 to 24 hpi. In comparison to non-infected cells, expression of 737 (Cluster 19) and 408 genes (Cluster 20) became up- or down-regulated at $36 \mathrm{hpi}$ in addition to the genes that had been differentially expressed since 12 or $24 \mathrm{hpi}$.

\section{Biological functions of genes in different expression clusters}

The biological consequences of the gene expression changes were analyzed using DAVID (The Database for Annotation, Visualization and Integrated Discovery) and are shown in Fig. 1 (left hand panel), and more detailed results are included in Additional file 1: Table S1. No significant functional categories can be identified by DAVID if the cluster contained few than 20 genes. The most significant functions of the genes in clusters 1 and 2 were stress response, cellular proliferation and apoptosis. A significant group of genes were cytokines, such as CXCL1, IL6, CCL2, CCL20, CXCL3, TNFSF15, IL1B, HGF, IL11, CXCL10, RALA, FGF2, FGF7, GDF15, AREG and HGF involving stress/immune response and cell growth control. Several genes that involved in apoptosis included MDM2, TNFAIP2, TNFAIP3, TNFAIP6, TNFAIP8, TNFSF15 and BIRC3 and involved in cell cycle control, such as CDKN1A, FYN, PLK2, AHR, and RGCC, were also noteworthy. Among transcription factors, up-regulation of ATF3 was the most significant and it increased 6-fold compared to the non-infected control. Expression of ATF3 has been shown to be induced by a variety of signals and it is involved in cellular stress response. Only 9 genes were present in cluster 5 and therefore no significant functional categories could be identified by DAVID. However, four (PTPN12, MAP4K3, ERRFI1 and LBH) out of the 9 genes, are involved in cellular signaling and growth control.

During the period between 6 and $12 \mathrm{hpi}$, adenovirus early genes begin to be expressed, redirecting cellular gene expression. The up-regulated cellular genes are involved in DNA replication (Clusters 6 and 7), including Minichromosome Maintenance Complex Components (MCM) $3,4,5,6,7$ and components of the post-replicative DNA mismatch repair system (MMR) alpha (MSH2-MSH6 heterodimer). In addition, genes implicate in transcription and pre-RNA processing were prominent in cluster 6 . Genes implicated in cell cycle were significant in Cluster 7, including CDC25A, CCNE2, CCNE1 and CDK2, the key regulators for the progression from $\mathrm{G} 1$ to the $\mathrm{S}$ phase. Although no significant function was identified for clusters 8 to 11, several genes, such as JunB, GADD45B and PAPPA function in control of cell growth and proliferation were included in this cluster. The most significant function for the down-regulated genes was actin cytoskeleton organization.
There was a dramatic increase in the number of differentially expressed genes between 12 and 24 hpi. Cellular genes which function in protein translation became significant among up-regulated genes. These genes covered both cytoplasmic and mitochondrial ribosomal proteins, eukaryotic translation initiation and elongation factors. Although genes involved in DNA replication and cell cycle were still significant, similar to those at $12 \mathrm{hpi}$, the number of genes in these categories increased dramatically. For instance, the number of genes involved in DNA metabolism/DNA replication increased from 18 to 124, whereas genes implicated in cell cycle increased from 19 to 153 . Most of these genes present in clusters 13, 14 and 15. The large number of genes involved in the cell cycle included many key regulators, such as E2Fs, cyclins, cyclin dependent kinases and cell division cycle (CDC) genes. In addition, genes participating in RNA processing became significant. Several important components of the exosome complex involved in the degradation and processing of a wide variety of RNA species were also up-regulated.

The number of down-regulated genes between 12 and 24 hpi also increased (Clusters 17 and 18). The most significant function of genes in these clusters was various growth factors and receptors. Cytoskeleton organization was significant for genes in cluster 17, whereas genes implicated in cell adhesion were significant in cluster 18 . Previous experiments have shown that the replication of Ad2 DNA reaches a maximum rate during the period from 24 to 36 hpi [44]. However, cellular gene expression was still maintained at a high level. The most significant function of the up-regulated genes (Cluster 19) was protein translation similar to that at $24 \mathrm{hpi}$, but with an increased number of genes. Genes involved in the generation of precursor metabolites and energy, as well as oxidation reduction became significant. In addition, several genes identified in different diseases were also significant. The major function for the down-regulated genes (Cluster 20) was cellular macromolecule catabolic processes such as ubiquitination and subsequent proteasome degradation of target proteins. Another significant function was small GTPase mediated signal transduction, involved in vesicle transport.

\section{Consensus transcription factor binding sites in the promoter region of genes in the different clusters} Genes sharing a similar transcription profile are likely to be regulated by common transcription factors (TF) or TFs from the same family. To this end, the genes in the 20 different clusters were subjected to analysis for the presence of consensus TF binding sites in their promoter regions $(-300$ to +100$)$ using Transfind [63]. The most over-represented TF binding sites are listed in the order of significance in Table 2. NFKB and c-Rel binding sites 
Table 2 Presence of consensus transcription factor binding sites in the -300 to +100 promoter sequence of differentially expressed genes in different clusters

\begin{tabular}{|c|c|c|c|c|c|c|c|c|c|}
\hline & Rank & Binding site & FDR & No. genes ${ }^{a}$ & & Rank & Binding site & FDR & No. genes ${ }^{a}$ \\
\hline \multirow[t]{2}{*}{ Cluster 1} & 1 & NF-kappaB & 0.000094 & 6 & & 6 & E2F & 0.000132 & 31 \\
\hline & 2 & c-Rel & 0.001353 & 5 & & 7 & USF & 0.000334 & 34 \\
\hline Cluster 6 & 1 & E2F & 0.005309 & 5 & & 8 & CREBATF/CREB, & 0.000334 & 22 \\
\hline Cluster 7 & 1 & E2F & 0.000527 & 6 & & 9 & NFY & 0.000845 & 21 \\
\hline \multirow[t]{7}{*}{ Cluster 13} & 1 & E2F & $<0.000001$ & 99 & & 10 & Egr-1 & 0.002093 & 20 \\
\hline & 2 & GABP & $<0.000001$ & 49 & Cluster 20 & 1 & Stra13 & $<0.000001$ & 23 \\
\hline & 3 & NRF1 & $<0.000001$ & 40 & & 2 & USF & 0.000007 & 19 \\
\hline & 4 & CREBP1CJUN/ATF2:C-Jun & $<0.000001$ & 35 & & 3 & c-Myc:Max & 0.000024 & 18 \\
\hline & 5 & AHRHIF/AhR, & $<0.000001$ & 35 & & 4 & CREBP1CJUN/ATF2:C-Jun & 0.000304 & 16 \\
\hline & 6 & STAT1 & $<0.000001$ & 34 & & 5 & CREBATF/CREB, & 0.000304 & 16 \\
\hline & 7 & CREBATF & $<0.000001$ & 33 & & 6 & GABP & 0.00081 & 15 \\
\hline \multirow[t]{3}{*}{ Cluster 14} & 1 & $\mathrm{E} 2 \mathrm{~F}$ & $<0.000001$ & 42 & & 7 & ATF6 & 0.00081 & 15 \\
\hline & 2 & CREBP1CJUN/ATF2:C-Jun & $<0.000001$ & 26 & & 8 & ATF4 & 0.00081 & 15 \\
\hline & 3 & NRF1/NRF-1 & $<0.000001$ & 24 & & 9 & ATF1 & 0.00273 & 14 \\
\hline
\end{tabular}

${ }^{a}$ The number of genes contain the consensus TR binding site

were most significant for the genes in cluster 1. Interesting genes among them were BIRC3, IKBA, CCL20, GROA (CXCL1), TNAP3 and TNF15, known to be involved in immune response or apoptosis. No significant enrichment of TF binding sites was identified for the genes in clusters 2, 3, 4, 5. For the genes in clusters 6 and 7 , only the E2F binding site was significant. More genes with E2F binding were identified in clusters 13 and 14. In addition, the binding sites for GABP, NRF1 and ATF/CREB family were significant among genes in clusters 13, 14 and 15, respectively. GABP regulates genes that are involved in cell cycle control, protein synthesis, and cellular metabolism. NRF1 activates the expression of key metabolic genes regulating cellular growth. The ATF/CREB family has diverse functions in controlling cell proliferation and apoptosis. In contrast, the TF binding sites among the down-regulated genes were less significant. Only the MZF1 and AP2 binding sites were scored but their significance was low and they were only present on 8 or 7 genes, respectively. MZF1 can function as a tumor/growth suppressor and controls cell proliferation and tumorigenesis [64]. At $36 \mathrm{hpi}$, different sets of TF binding sites became significant for up-regulated genes (Cluster 19), including SP1, STRA13 and NF-Y in addition to GABP while the binding sites for E2F became less significant. This correlated very well with the expression profile of E2Fs. Expression of all E2Fs increased at 12 and $24 \mathrm{hpi}$, and then decreased at $36 \mathrm{hpi}$. The TF binding sites for the down-regulated genes were less significant and STRA13 and USF were on the top of the list. STRA13 is a transcriptional repressor. Correspondingly, its expression increased 4 and 8 times at 
24 and 36 hpi, respectively. STRA13 is involved in DNA damage repair and genome maintenance. Surprisingly, the STRA13 binding site was significant for both up- and down-regulated genes at $36 \mathrm{hpi}$. Its transcriptional repression is probably mediated by recruitment of other regulatory factors and, depending on the cofactors, STRA13 plays divergent roles. USF that binds to a symmetrical DNA sequence (E-boxes; 5-CACGTG-3) is involved in the transcriptional activation of various genes implicated in physiological processes, such as stress response, immune response, cell cycle control and tumor growth.

\section{Comparison of RNA and protein expression profiles for the genes involved in cellular immune pathways}

Cellular immune network is a major target during Ad2 infection. As shown above, the transcription of genes involved in immune response displayed very dramatic changes, being transiently up-regulated at $6 \mathrm{hpi}$ before becoming down-regulated after $24 \mathrm{hpi}$. The expression of these genes at protein level was also analyzed. The protein expression data was retrieved from our early study $[48,65]$. Our previous data analysis of the functions of differentially expressed proteins was mainly relied on a web-based tool DAVID, a functional enrichment analysis by integrating wide-range heterogeneous data. Thus, it is less ideal for analysis of virus-induced changes in gene expression because of underrepresentation of genes related to virus infection. Specifically, the expression of proteins involved in cellular immune pathways remained to be studied. Here, we identified many key regulators in cellular immune pathways that displayed inconsistent expression profiles between RNA and protein expression as listed in Table 3. Their expression profiles are shown in Fig. 2.

As presented above, $\mathrm{NF}_{\kappa} \mathrm{B}$ and c-Rel binding sites were the most significant in the promoter regions of genes that were transiently up-regulated during the early phase. Correspondingly, expression of several key factors of the NFkB pathway was activated at both the RNA and protein levels during the early phase (Fig. 2a). The transcription of all $N F \kappa B$ family members was detectable, and NFKB1 was the most highly expressed. Except REL, all showed very similar expression profiles. Specifically, they were moderately induced during the early phase, but decreased rapidly and became down-regulated after 24 hpi. Among them, expression of RELA, NFKB1 and NFkB2 was also detected at the protein level. Coupled with the increased RNA level at $6 \mathrm{hpi}$, these proteins were also up-regulated. Unexpectedly the NFkB2 and RELA protein levels remained constant until the late phase in spite of the reduction in transcription. The members of NFkB inhibitor family (I $\mathrm{KB}$ ) displayed diverse transcription profiles. NFKBIA ( $I \kappa B \alpha)$ and NFKBIZ $(\mathrm{I} B \mathrm{~B} \zeta)$ were the most highly expressed and showed similar expression profiles, transiently up-regulated at 6 hpi but decreased at $12 \mathrm{hpi}$ and were reduced more than 8 -fold at 36 hpi. NFкBIB (ІкBß) showed an opposite expression pattern, low in uninfected cells and at $6 \mathrm{hpi}$, but increased after $12 \mathrm{hpi}$ and became up-regulated more than 16-fold at 36 hpi. Thus, it appears that NFKBIB replaced NFKBIA to be the most highly expressed IкB in the late phase. None of these gene products was detected at the protein level. The expression changes of the inhibitors of NFKB kinases (IKKs) subunit, IKBKB, and its regulatory subunit IKBKG, as well as IKK-related kinases, IKBKE and TBK1, appeared to be coordinated. They were delayed as compared to the expression of $\mathrm{NF} \kappa \mathrm{Bs}$ and IKBs and significant down-regulation of transcription occurred at 24 or 36 hpi. A surprising finding was that the expression of IKBKB and TBK1 was up-regulated at the protein level. The IKBKB protein was up-regulated already at $6 \mathrm{hpi}$ and remained stable until the late phase while the up-regulation of the TBK1 protein was significant after $24 \mathrm{hpi}$. The results thus indicate that the positive regulators of the $\mathrm{NFKB}$ pathway are activated at both the RNA and protein levels during the early phase as result of the host immediate response to the infection. Following the progression of the infection, these proteins remained up-regulated until $36 \mathrm{hpi}$ although their transcription was suppressed.

The Janus kinase-signal transducer and activator of transcription (JAK/STAT) signaling is another important pathway regulating the innate immune response. Transcription of all six STATs was unchanged up to $12 \mathrm{hpi}$, but was then down-regulated after $24 \mathrm{hpi}$ (Table 3). Four STAT proteins (STAT1, STAT2, STAT3 and STAT6) were detected and they were up-regulated during the early phase and remained stable or decreased slightly in the late phase. JAKs are important activators of STAT and catalyze the phosphorylation of the STAT proteins. The three JAK kinases, JAK1, JAK2 and TYK2, displayed different expression profiles. JAK1 was the most highly transcribed and increased only slightly at $6 \mathrm{hpi}$. Then, it decreased to the basic level and remained constant until the late phase. Transcription of both JAK2 and TYK2 increased at 12 hpi. JAK2 decreased during the late phase while TYK2 remained constant. Only JAK1 protein was detected and it decreased slightly during the early phase, but became up-regulated at 24 hpi. The activity of the STAT proteins is also controlled by several negative regulators, including protein tyrosine phosphatase (PTPN), suppressor of cytokine signaling (SOCS) and protein inhibitor of activated STAT (PIAS). Several PTPNs were detected at both RNA and protein levels with inconsistent expression profiles. However, several Importins and Ran, required for nuclear translocation of STATs, were up-regulated at both at the RNA and protein levels during the infection. 


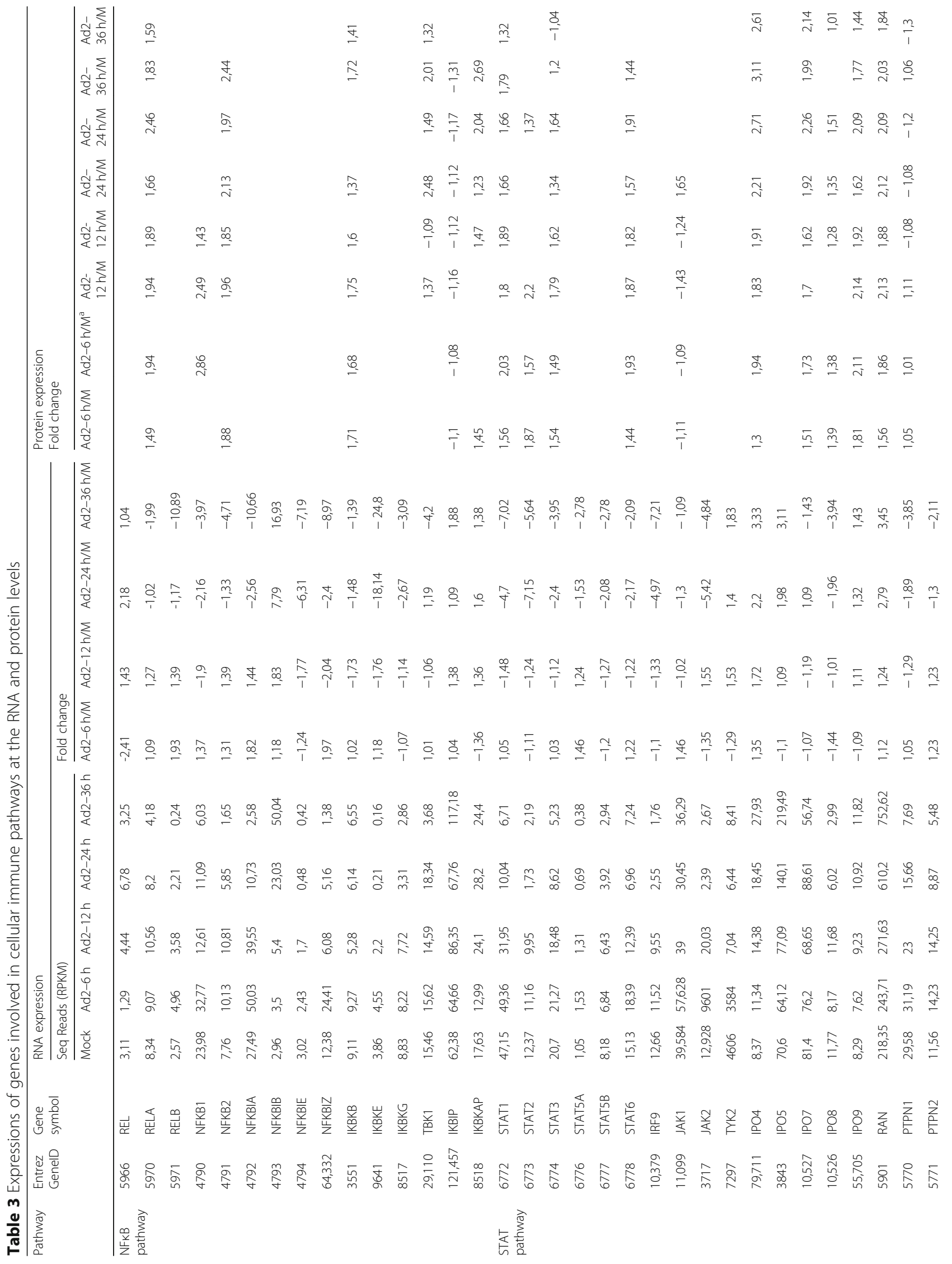




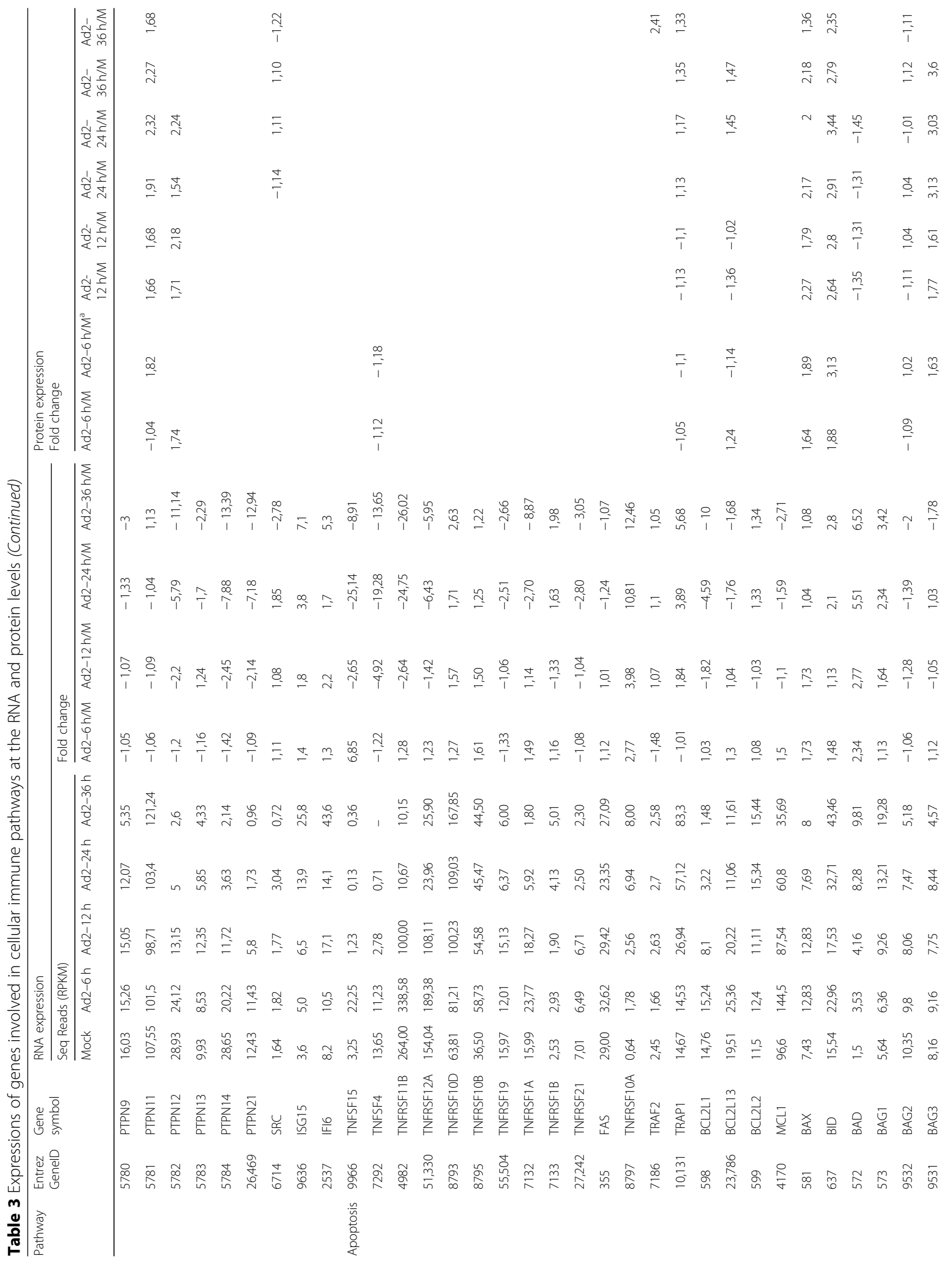




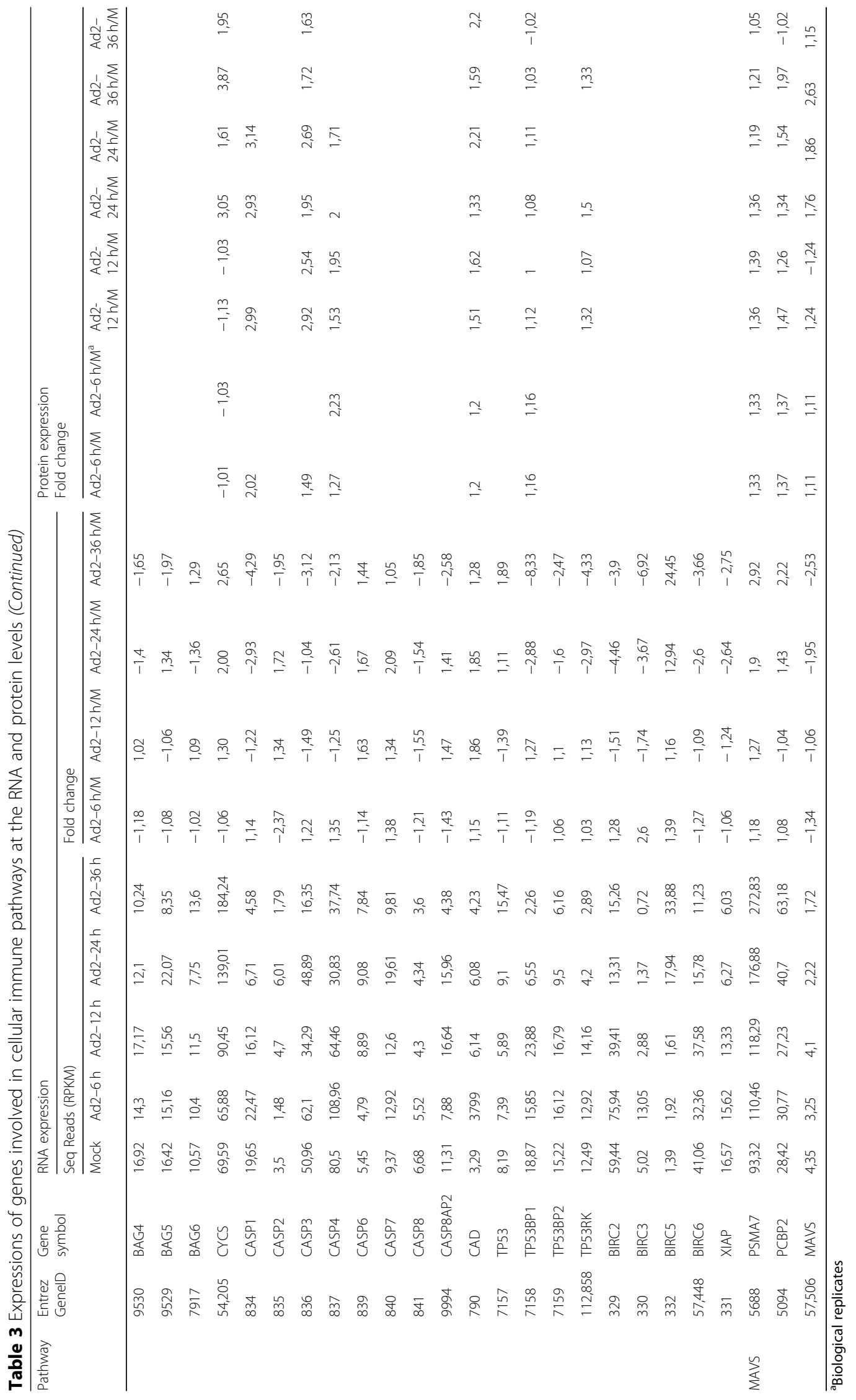




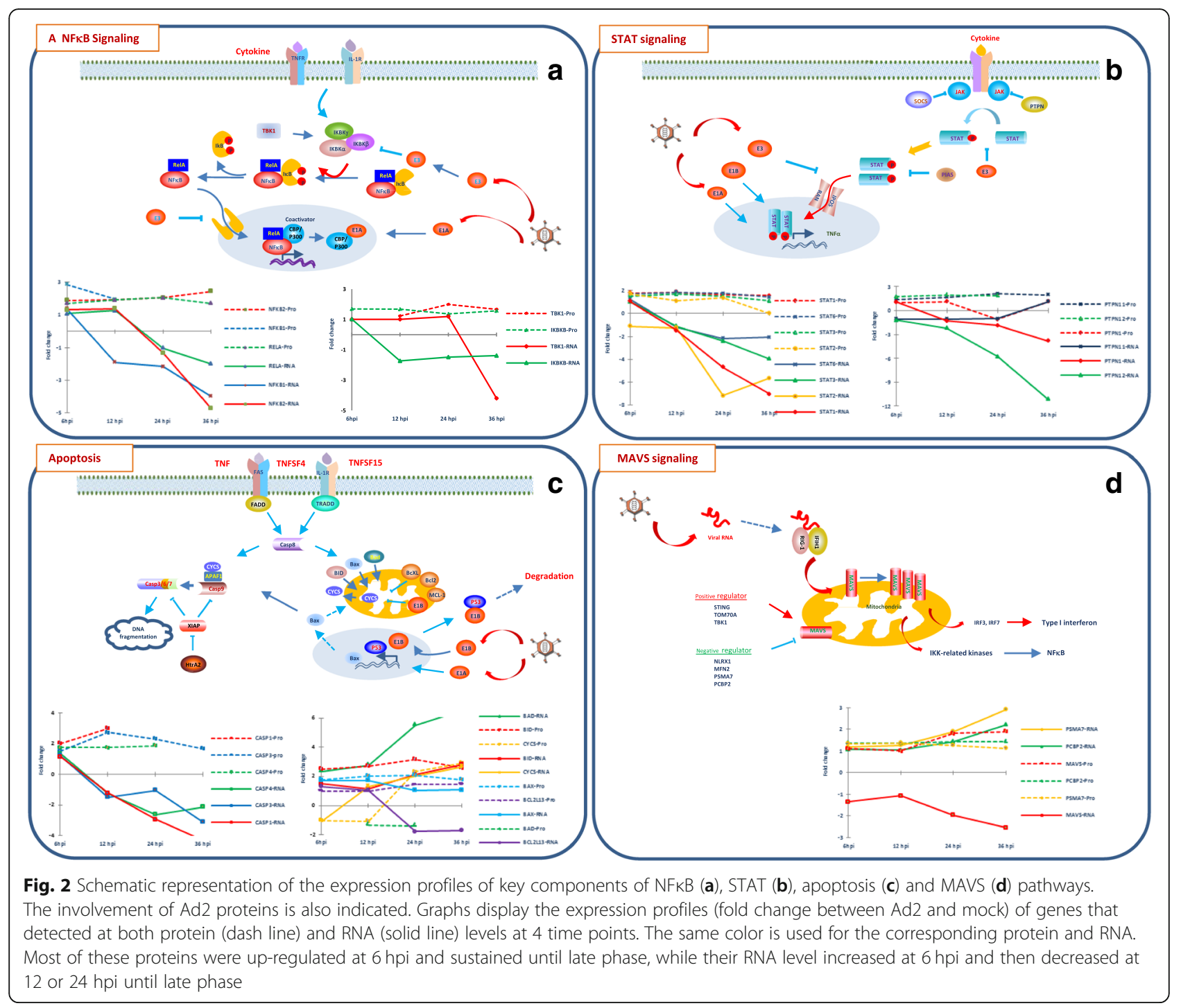

Apoptosis pathways are extensively regulated during Ad2 infection. Our RNA sequencing results showed that transcription of more than $60 \%$ of genes that are directly involved in apoptosis were down-regulated, whereas only $20 \%$ were up-regulated in the late phase (data not shown). Transcription of most TNF family ligands was undetectable or at a very low level except for TNFSF15 and TNFSF4 (Table 3). Both of them decreased after $12 \mathrm{hpi}$, although TNFSF15 was transiently induced more than 6 -fold at 6 hpi. Numerous TNF receptor superfamily members were expressed at the transcriptional level with diverse expression profiles. TNFRSF11B and TNFRSF12A were the most highly expressed receptors, their RNA levels decreased at $12 \mathrm{hpi}$ and were then more than 25- and 6-fold down-regulated at $36 \mathrm{hpi}$. Unfortunately, none of the TNF receptor superfamily members was detected at the protein level.
Caspases (CASPs) and the Bcl2 families are key players in apoptosis. At the transcriptional level, CASPs showed different expression profiles. Among them, CASP1, 3 and 4 are most highly expressed with similar expression profiles, slightly increased at $6 \mathrm{hpi}$ and then down-regulated. All of these CASPs were detected at the protein level and were up-regulated, opposite to their RNA expression profile. Expressions of most $\mathrm{Bcl} 2$ family members were low at the RNA level except for those listed in the Table 3. Transcriptions of most anti-apoptotic BCLs (BCL2A1, BCL2L1, BCL2L13 and MCL1) were down-regulated after a slight increase at $6 \mathrm{hpi}$. Among them, only BCL2L13 protein was detected which showed $40 \%$ increased expression during the late phase. Among pro-apoptotic genes, transcription of BID, BAD and BAX was up-regulated gradually towards the late phase or remained stable. At the protein level, BID and BAX were up-regulated from the early to the late phase, although the RNA level for BAX decreased in the 
late phase. BAD protein displayed an expression pattern opposite to its RNA. BAD protein level was more than $30 \%$ lower than in mock at 12 and 24 hpi although its RNA was 2- and 5-fold higher than in uninfected control at 12 and $24 \mathrm{hpi}$, respectively.

Inconsistent expression profiles between RNA and protein for the genes involved in MAVS was shown in our previous study [48]. We show here that expression of MAVS is stable at both RNA and protein levels during the early phase, whereas a difference was seen in the late phase. In addition, we have studied the expression of three MAVS regulatory proteins, PSMA7, PCBP2 and TBK1. The expression profiles of the negative regulators PSMA7 and PCBP2 were similar at both the RNA and protein levels, and increased slowly during infection. The positive regulator, TBK1 showed an opposite profile; its RNA was down-regulated at $36 \mathrm{hpi}$ whereas its protein level increased after $24 \mathrm{hpi}$. In spite of the up-regulation of MAVS and its positive regulator, expression of the target genes (type I interferon genes) was very low or undetectable, suggesting that this antivirus pathway is inactivated during the late phase.

Furthermore, different expression profiles were also observed for galectins LGALS. LGALS3 and 8 (Gal3 and 8) were the most highly expressed among LGALSs and their RNAs were down-regulated after 24 hpi (for more details see Additional file 1: Table S1). However, their proteins remained constant from early to late phase. Galectins have been shown to be involved in innate immune processes [66]. Colocalization of LGALS3 with incoming Ad5 has been observed and its role in Ad5 transport was suggested [67]. Stable expression of LGALS3 has been reported previously in Ad5-infected cells, while it is down-regulated in Ad3-infected cells [68].

\section{Discussion}

Our transcriptomic analysis showed that the alteration of cellular gene expression correlated with the progression of adenovirus infection and that only specific sets of cellular genes were targeted at the different stages of the infection. The most dramatic changes in transcription profile occurred during the early phase although the most significant increase in the number of differentially expressed genes occurred at $24 \mathrm{hpi}$ as infection proceeded into the late phase. About $80 \%$ of up-regulated genes at 6 hpi were only transiently induced and their expression decreased after $12 \mathrm{hpi}$ and became down-regulated after 24 hpi. A significant group of these genes encode cytokines, including CXCL1, IL6, CCL2, CCL20, CXCL3, TNFSF15, IL1B, HGF, IL11, CXCL10, RALA, FGF2, FGF7, GDF15, AREG and HGF involved in cellular immune response and cell growth control. Genes involved in apoptosis included MDM2, TNFAIP2, TNFAIP3, TNFAIP6, TNFAIP8, TNFSF15 and BIRC3. Genes involved in cell cycle control, such as CDKN1A, FYN, PLK2, AHR, and RGCC, were also noteworthy. Induction of cytokines by adenovirus has been shown in in vivo studies with rodent and primate animal systems and in human clinical trials [69]. Up-regulation of cytokine expressions most likely represents the host immediate response to Ad2 infection, triggered by the attachment of virus to membrane receptors, the entry process and intracellular transport, as well as Ad2-encoded small RNAs that are produced before any viral protein is translated [70]. It has been shown that MAPK cascades are the key components of the signaling networks that sense cell exposure to environmental stimulation. Stimulation of the Raf/MAPK signaling pathway will activate $\mathrm{NF} k \mathrm{~B}$ and $\mathrm{AP}-1$. Although consensus transcription factor binding sites analysis showed that $\mathrm{NFkB}$ and c-Rel binding site were most significant for the immune response genes in cluster 1, these transcription factors are only responsible for the activation. The rapid decrease of the first wave of up-regulated genes correlated with the expression of Ad2 E1. It has been shown that the interaction of E1A with the coactivators p300/CBP disrupts the histone acetyltransferase activity of p300/CBP and their associated factor PCAF, leading to decreased transcription from a variety of different genes involved in growth arrest, cell differentiation and immune evasion $[4,5,8,9,11-14]$. In addition, small E1A forms a complex with hypophosphorylated pRB1 and p300, and recruits the complex to the gene bodies and represses gene expression [17]. Particularly, many proteins in TGF $\beta$, TNF and interleukin signaling pathways have been shown to be enriched among p300-E1A-pRB complex targets. Thus, suppression of the host early antiviral response is mainly credited to the function of small E1A protein.

Following the expression of E1A at $12 \mathrm{hpi}$, the number of differentially expressed genes increased, and down-regulated genes became more significant (Cluster 12). In addition, 28 genes in cluster 1 that were up-regulated at $6 \mathrm{hpi}$ were down-regulated. Gene ontology analysis showed that genes up-regulated at $12 \mathrm{hpi}$ (Cluster 6 and 7) were enriched for S phase genes. In agreement with the fact that E2F is a target for E1A-mediated activation, E2F transcription factor binding sites were highly significant among up-regulated genes. Thus, deregulation of the cell cycle is mainly ascribed to the ability of the E1A proteins to bind members of pRB family, permitting E2F to activate genes required in S-phase [3, 7]. Although no significant enrichment of TF binding sites was identified for the suppressed genes at $12 \mathrm{hpi}$ for cluster, the E1A protein undoubtedly plays an important role as discussed above. Many genes in clusters 1 and 12, such as THBS1, CTGF, CYR61, KLF6, KLF10, NFKBIA, ATF3, IL6, and F3 are known to be associated with p300-E1A-pRB [17].

When adenovirus DNA replication reached its efficient mode at $24 \mathrm{hpi}$, the number of differentially expressed genes 
was dramatically increased. Significantly, transcription factors CREB and CREBP1:CJUN (ATF2:CJUN) binding sites became abundant in up-regulated genes. E1A has been shown to cooperate with CREB to regulate host cell gene expression [71, 72]. While promotion of ATF2:CJUN-dependent genes expression by the $\mathrm{N}$-terminus of E1A has also been shown [73]. There is a relatively stable period from 24 to $36 \mathrm{hpi}$ as compared to that from 6 to $12 \mathrm{hpi}$. The consensus Sp1 binding sites are the most common in the up-regulated genes. These results are consistent with our early studies using cDNA microarray [74]. Although no significant consensus transcription factor binding sites were identified for down-regulated genes at $12 \mathrm{hpi}$, E1A most likely play an important role for the repression of these genes, as discussed above. The most significant transcription factor binding sites for the down-regulated genes at $24 \mathrm{hpi}$ (Cluster 17) were ATF2 and CREB.

Many key regulators of cellular immune response showed different expression profiles at RNA and protein levels. Three important NFkB family members RELA, $\mathrm{NF} \kappa \mathrm{B} 1$ and $\mathrm{NF} \kappa \mathrm{B} 2$ were up-regulated at the protein level during the early phase and remained stable until late phase although their transcription was suppressed. However, the fact that the downstream target genes of the $\mathrm{NF} K \mathrm{~B}$ pathway were down-regulated during the late phase indicates that these proteins have lost their functions as transcriptional activators. The dramatic up-regulation of NFKIB may contribute to the inhibition of the NFKB activity. Other post-translational control mechanisms, such as the blocking of the nuclear transport, loss of coactivators such as CBP/P300, p400 and TRAPP due to interaction with the Ad2 E1A protein, may contribute to the block of the $\mathrm{NFK}_{\mathrm{K}} \mathrm{B}$ activity $[75,76]$. Additional yet unidentified mechanism might also cause the inactivation of the $\mathrm{NF \kappa B}$ pathway.

Similar to NFkB pathway, several key players in STAT signaling pathway were also activated at both RNA and protein levels during the early phase of infection. Although their transcription was suppressed during the late phase, their protein levels remained stable. The expression of downstream targets of the STAT pathway differed, however, illustrating the complexity of the regulation of STAT pathway. The activity of STATs has been shown to be modulated by various posttranslational modifications [77, 78]. Upon infection, adenovirus uses several strategies to block the STAT pathway. The viral E1A plays a role in the inactivation of the STAT pathway by binding to STATs, or their coactivator $\mathrm{CBP} / \mathrm{p} 300$ acetyltransferases $[13,15,79,80]$. In addition, E1A directly binds to hBre1/ RNF20 complex and blocks IFN-induced H2B monoubiquitination of histone $2 \mathrm{~B}$, resulting in suppression of ISGs [16]. A recent study shows that $C$ terminus of E1A interacts with RuvBL1/pontin and suppresses RuvBL1/ pontin-mediated activation of ISGs [81]. Expression of RuvBL1 at both RNA and protein levels were detected in our study, and they remained stable during infection. Furthermore, the E1B-55 $\mathrm{k}$ protein represses expression of IFN-inducible genes which leads to the inhibition of the STAT signaling pathway [82]. E3-14.7 K protein interacts with STAT1 which results in the inhibition of STAT1 phosphorylation and nuclear translocation [83]. Phosphorylated STAT1 has been shown to be sequestered at viral replication centers in the nucleus [84]. The increased expression of STAT proteins indicates that STAT pathway might not be blocked. Furthermore, some ISGs were still actively transcribed even in the late phase, such as ISG15, IFIT1 and IFI6. Their transcriptions increase continued during infection and reached more than 4-fold at 36 hpi as compared to the non-infected control (for more details see Additional file 1: Table S1). Regulation of STAT gene expression apparently reflects the complexity of the battle between the virus and its host.

Although most genes that are directly involved in apoptosis were down-regulated at the transcriptional level during the late phase, several important pro-apoptotic players remained up-regulated at the protein level (CASP3, BAX and BID). The fact that apoptosis is efficiently inhibited during an adenovirus infection indicates that the functions of these proteins must be blocked. To counteract the host defensive apoptotic pathways, adenoviruses have established very efficient mechanisms by encoding their own anti-apoptotic proteins in the E1B and E3 regions [85, 86]. In addition, E1A can also block p53 transcriptional activation through sequestration of p300/CBP [87]. Thus, the regulation of apoptosis is very multifaceted.

The facts that most of downstream genes of immune pathways are down-regulated at RNA level during the late phase even though their key regulators are stable or up-regulated at the protein level, indicate that adenovirusmediated post-translational mechanisms play an important role. As discussed above, inhibition of STAT pathway represents a good example of how adenovirus has evolved redundant strategies to counteract cellular immune response. By regulating protein modification, blocking of protein-protein interactions, inhibiting of the protein transport to its destination, adenovirus apparently controls host cell antiviral pathways. Last but not least, non-coding RNAs (ncRNAs) are known to be important regulators of various biological processes. Alterations of cellular miRNA and lncRNA expression during Ad2 infection have been studied using RNA-seq $[46,47]$. Significant changes in their expression take place after 24 hpi. The strong correlation of ncRNA expression changes with infection progression indicates that ncRNA play important roles. A majority of differentially expressed miRNAs were down-regulated during the late phase. One major mechanism by which miRNA regulates gene 
expression is by suppression of translation through partial complementarity to 3' UTRs of mRNA. Thus, downregulation of miRNAs could lead to altered translation of special sets of proteins. In contrast, most differentially expressed cellular lncRNAs were up-regulated in the late phase while several lncRNAs that are predicted to target immune response genes were down-regulated during the late phase. In addition, a large share of differentially expressed lncRNAs are associated with RNA-binding proteins (RBPs), being involved in posttranscriptional RNA processing and translation regulation. However, how they are regulated, and how they are involved in the regulation of cellular gene expression during adenovirus infection needs to be further addressed.

\section{Conclusion}

There were features common to genes which play important roles in cellular immune pathways. Their expression was stimulated at both RNA and protein levels during the early phase. In the late phase however, their transcription was suppressed while proteins level remained stable. These results indicate that $\mathrm{Ad} 2$ and the host use different strategies to regulated cellular immune pathways. A control mechanism at the post-translational level must thus exist which is under the control of $\mathrm{Ad} 2$.

\section{Additional file}

Additional file 1: Analysis of differetially expressed cellular genes in Ad2-infected cells. (XLS $1117 \mathrm{~kb}$ )

\section{Abbreviations}

Ad2: Adenovirus type 2; DAVID: The Database for Annotation, Visualization and Integrated Discovery; FPKM: Fragments per kilobase per million reads mapped; IMR-90 cell: Human lung fibroblast; MS: Mass spectrometry; SILAC: Stable Isotope Labelling of Amino acids in Cell culture

\section{Acknowledgments}

Sequencing was performed at the SNP\&SEQ Technology Platform at Uppsala University and University Hospital. We thank Ulrika Liljedahl and Johanna Lagensjö for excellent sequencing. Martin Dahlö at UPPMAX is

acknowledged for helping to make the code run on the UPPMAX resources.

\section{Funding}

This work was supported by the Kjell and Märta Beijer Foundation (UP), Clas Groschinsky Foundation (SBL), Swedish Foundation for Strategic Research (SBL).

\section{Availability of data and materials}

Datasets used in the current study are available upon request.

\section{Authors' contributions}

$\mathrm{HZ}$ and UP conceived and designed the experiments; $\mathrm{HZ}$ performed the experiments. MC did the data analysis. SL and AD provided the MS data. HZ and UP wrote the manuscript. All authors read and approved the final manuscript. TF: transcription factors.

\section{Ethics approval and consent to participate}

Not applicable.

\section{Consent for publication}

Not applicable.

\section{Competing interests}

The authors declare that they have no competing interests.

\section{Publisher's Note}

Springer Nature remains neutral with regard to jurisdictional claims in published maps and institutional affiliations.

\section{Author details}

${ }^{1}$ The Beijer laboratory, Department of Immunology, Genetics and Pathology, Uppsala University, S-751 85 Uppsala, Sweden. ²Australian Centre for Blood Diseases, Central Clinical school, Monash University, Clayton, Australia. ${ }^{3}$ Department of Analytical Chemistry, Physical Chemistry and Chemical Engineering, University of Alcalá, Alcalá de Henares, Madrid, Spain.

${ }^{4}$ Department of Chemistry-BMC, Analytical Chemistry, Uppsala University, Box 599, SE-751 24 Uppsala, Sweden.

Received: 16 July 2018 Accepted: 16 December 2018

Published online: 14 January 2019

References

1. Ferrari R, Pellegrini M, Horwitz GA, Xie W, Berk AJ, Kurdistani SK. Epigenetic reprogramming by adenovirus e1a. Science. 2008:321(5892):1086-8.

2. Flint J, Shenk T. Viral transactivating proteins. Annu Rev Genet. 1997;31:177-212.

3. Bayley ST, Mymryk JS. Adenovirus e1a proteins and transformation (review). Int J Oncol. 1994;5(3):425-44.

4. Braun $\mathrm{T}$, Bober $\mathrm{E}$, Arnold $\mathrm{HH}$. Inhibition of muscle differentiation by the adenovirus E1a protein: repression of the transcriptional activating function of the HLH protein Myf-5. Genes Dev. 1992;6(5):888-902.

5. Caruso M, Martelli F, Giordano A, Felsani A. Regulation of MyoD gene transcription and protein function by the transforming domains of the adenovirus E1A oncoprotein. Oncogene. 1993;8(2):267-78.

6. Chellappan S, Kraus VB, Kroger B, Munger K, Howley PM, Phelps WC, Nevins $\mathrm{JR}$. Adenovirus E1A, simian virus 40 tumor antigen, and human papillomavirus E7 protein share the capacity to disrupt the interaction between transcription factor E2F and the retinoblastoma gene product. Proc Natl Acad Sci U S A. 1992;89(10):4549-53.

7. Cobrinik D. Regulatory interactions among E2Fs and cell cycle control proteins. Curr Top Microbiol Immunol. 1996;208:31-61.

8. Chakravarti D, Ogryzko V, Kao HY, Nash A, Chen H, Nakatani Y, Evans RM. A viral mechanism for inhibition of p300 and PCAF acetyltransferase activity. Cell. 1999;96(3):393-403.

9. Reid JL, Bannister AJ, Zegerman P, Martinez-Balbas MA, Kouzarides T. E1A directly binds and regulates the P/CAF acetyltransferase. EMBO J. 1998; 17(15):4469-77.

10. Chinnadurai G. Modulation of oncogenic transformation by the human adenovirus E1A C-terminal region. Curr Top Microbiol Immunol. 2004;273: 139-61.

11. Arany Z, Newsome D, Oldread E, Livingston DM, Eckner R. A family of transcriptional adaptor proteins targeted by the E1A oncoprotein. Nature. 1995;374(6517):81-4.

12. Bannister AJ, Kouzarides T. CBP-induced stimulation of c-Fos activity is abrogated by E1A. EMBO J. 1995;14(19):4758-62.

13. Bhattacharya S, Eckner R, Grossman S, Oldread E, Arany Z, D'Andrea A, Livingston DM. Cooperation of Stat2 and p300/CBP in signalling induced by interferon-alpha. Nature. 1996:383(6598):344-7.

14. Missero C, Calautti E, Eckner R, Chin J, Tsai LH, Livingston DM, Dotto GP. Involvement of the cell-cycle inhibitor Cip1/WAF1 and the E1A-associated p300 protein in terminal differentiation. Proc Natl Acad Sci U S A. 1995; 92(12):5451-5.

15. Ackrill AM, Foster GR, Laxton CD, Flavell DM, Stark GR, Kerr IM. Inhibition of the cellular response to interferons by products of the adenovirus type 5 E1A oncogene. Nucleic Acids Res. 1991;19(16):4387-93.

16. Fonseca GJ, Thillainadesan G, Yousef AF, Ablack JN, Mossman KL, Torchia J, Mymryk JS. Adenovirus evasion of interferon-mediated innate immunity by direct antagonism of a cellular histone posttranslational modification. Cell Host Microbe. 2012;11(6):597-606.

17. Ferrari R, Gou D, Jawdekar G, Johnson SA, Nava M, Su T, Yousef AF, Zemke NR, Pellegrini M, Kurdistani SK, et al. Adenovirus small E1A employs the lysine acetylases p300/CBP and tumor suppressor Rb to repress select host genes and promote productive virus infection. Cell Host Microbe. 2014; 16(5):663-76. 
18. Zemke NR, Berk AJ. The adenovirus E1A C terminus suppresses a delayed antiviral response and modulates RAS signaling. Cell Host Microbe. 2017; 22(6):789-800 e785.

19. Berhane S, Areste C, Ablack JN, Ryan GB, Blackbourn DJ, Mymryk JS, Turnell AS, Steele JC, Grand RJ: Adenovirus E1A interacts directly with, and regulates the level of expression of, the immunoproteasome component MECL1 Virology 2011, 421(2):149-158.

20. Harada JN, Shevchenko A, Shevchenko A, Pallas DC, Berk AJ. Analysis of the adenovirus E1B-55K-anchored proteome reveals its link to ubiquitination machinery. J Virol. 2002;76(18):9194-206.

21. Querido E, Blanchette P, Yan Q, Kamura T, Morrison M, Boivin D, Kaelin WG, Conaway RC, Conaway JW, Branton PE. Degradation of p53 by adenovirus E4orf6 and E1B55K proteins occurs via a novel mechanism involving a Cullin-containing complex. Genes Dev. 2001;15(23):3104-17.

22. Schwartz RA, Lakdawala SS, Eshleman HD, Russell MR, Carson $C T$, Weitzman MD. Distinct requirements of adenovirus E1b55K protein for degradation of cellular substrates. J Virol. 2008;82(18):9043-55.

23. Farrow SN, White JH, Martinou I, Raven T, Pun KT, Grinham CJ, Martinou JC, Brown R. Cloning of a bcl-2 homologue by interaction with adenovirus E1B 19K. Nature. 1995;374(6524):731-3.

24. Han J, Sabbatini P, Perez D, Rao L, Modha D, White E. The E1B 19K protein blocks apoptosis by interacting with and inhibiting the p53-inducible and death-promoting Bax protein. Genes Dev. 1996;10(4):461-77.

25. Cuconati A, Mukherjee C, Perez D, White E. DNA damage response and MCL-1 destruction initiate apoptosis in adenovirus-infected cells. Genes Dev. 2003;17(23):2922-32.

26. Wold WS, Tollefson AE, Hermiston TW. E3 transcription unit of adenovirus. Curr Top Microbiol Immunol. 1995;199(Pt 1):237-74.

27. Bennett EM, Bennink JR, Yewdell JW, Brodsky FM. Cutting edge: adenovirus E19 has two mechanisms for affecting class I MHC expression. J Immunol. 1999;162(9):5049-52.

28. Burgert HG, Kvist $\mathrm{S}$. The E3/19K protein of adenovirus type 2 binds to the domains of histocompatibility antigens required for $C T L$ recognition. EMBO J. 1987;6(7):2019-26.

29. Wold WS, Doronin K, Toth K, Kuppuswamy M, Lichtenstein DL, Tollefson AE. Immune responses to adenoviruses: viral evasion mechanisms and their implications for the clinic. Curr Opin Immunol. 1999;11(4):380-6.

30. Tollefson AE, Toth K, Doronin K, Kuppuswamy M, Doronina OA, Lichtenstein DL, Hermiston TW, Smith CA, Wold WS. Inhibition of TRAlL-induced apoptosis and forced internalization of TRAIL receptor 1 by adenovirus proteins. J Virol. 2001;75(19):8875-87.

31. Friedman JM, Horwitz MS. Inhibition of tumor necrosis factor alpha-induced NF-kappa B activation by the adenovirus E3-10.4/14.5K complex. J Virol. 2002;76(11):5515-21.

32. Neill SD, Hemstrom C, Virtanen A, Nevins JR. An adenovirus E4 gene product trans-activates E2 transcription and stimulates stable E2F binding through a direct association with E2F. Proc Natl Acad Sci U S A. 1990;87(5):2008-12.

33. Obert S, O'Connor RJ, Schmid S, Hearing P. The adenovirus E4-6/7 protein transactivates the E2 promoter by inducing dimerization of a heteromeric E2F complex. Mol Cell Biol. 1994;14(2):1333-46.

34. Leppard KN, Everett RD. The adenovirus type 5 E1b 55K and E4 Orf3 proteins associate in infected cells and affect ND10 components. J Gen Virol. 1999:80(Pt 4):997-1008.

35. Doucas V, Ishov AM, Romo A, Juguilon H, Weitzman MD, Evans RM, Maul GG. Adenovirus replication is coupled with the dynamic properties of the PML nuclear structure. Genes Dev. 1996;10(2):196-207.

36. Kleinberger T, Shenk T. Adenovirus E4orf4 protein binds to protein phosphatase $2 A$, and the complex down regulates E1A-enhanced junB transcription. J Virol. 1993;67(12):7556-60.

37. Marcellus RC, Chan H, Paquette D, Thirlwell S, Boivin D, Branton PE. Induction of p53-independent apoptosis by the adenovirus E4orf4 protein requires binding to the Balpha subunit of protein phosphatase 2A. J Virol. 2000;74(17):7869-77

38. Branton PE, Roopchand DE. The role of adenovirus E4orf4 protein in viral replication and cell killing. Oncogene. 2001;20(54):7855-65.

39. Cuesta R, Xi Q, Schneider RJ. Adenovirus-specific translation by displacement of kinase Mnk1 from cap-initiation complex elF4F. EMBO J. 2000;19(13):3465-74

40. Farley DC, Brown JL, Leppard KN. Activation of the early-late switch in adenovirus type 5 major late transcription unit expression by $L 4$ gene products. J Virol. 2004;78(4):1782-91.
41. Hayes BW, Telling GC, Myat MM, Williams JF, Flint SJ. The adenovirus L4 100-kilodalton protein is necessary for efficient translation of viral late mRNA species. J Virol. 1990;64(6):2732-42.

42. Bridge $\mathrm{E}$, Ketner $\mathrm{G}$. Interaction of adenoviral $\mathrm{E} 4$ and $\mathrm{E} 1 \mathrm{~b}$ products in late gene expression. Virology. 1990;174(2):345-53.

43. Flint SJ, Gonzalez RA. Regulation of mRNA production by the adenoviral E1B 55-kDa and E4 Orf6 proteins. Curr Top Microbiol Immunol. 2003;272:287-330.

44. Zhao H, Granberg F, Pettersson U. How adenovirus strives to control cellular gene expression. Virology. 2007;363(2):357-75.

45. Shenk T: Adenoviridae: the viruses and their replication: Lippincott-Raven; 3rd edition edition (1996); 1996.

46. Zhao $H$, Chen M, Lind SB, Pettersson U. Distinct temporal changes in host cell IncRNA expression during the course of an adenovirus infection. Virology. 2016:492:242-50.

47. Zhao $\mathrm{H}$, Chen $\mathrm{M}$, Tellgren-Roth $\mathrm{C}$, Pettersson U. Fluctuating expression of microRNAs in adenovirus infected cells. Virology. 2015;478:99-111.

48. Zhao H, Konzer A, Mi J, Chen M, Pettersson U, Lind SB. Posttranscriptional regulation in adenovirus infected cells. J Proteome Res. 2017;16(2):872-88.

49. Miller DL, Myers CL, Rickards B, Coller HA, Flint SJ. Adenovirus type 5 exerts genome-wide control over cellular programs governing proliferation, quiescence, and survival. Genome Biol. 2007:8(4):R58.

50. Yates JR, Ruse Cl, Nakorchevsky A. Proteomics by mass spectrometry: approaches, advances, and applications. Annu Rev Biomed Eng. 2009:11:49-79.

51. Ong SE, Mann M. A practical recipe for stable isotope labeling by amino acids in cell culture (SILAC). Nat Protoc. 2006;1(6):2650-60.

52. Lam YW, Evans VC, Heesom KJ, Lamond Al, Matthews DA. Proteomics analysis of the nucleolus in adenovirus-infected cells. Mol Cell Proteomics. 2010;9(1):117-30.

53. Evans VC, Barker G, Heesom KJ, Fan J, Bessant C, Matthews DA. De novo derivation of proteomes from transcriptomes for transcript and protein identification. Nat Methods. 2012;9(12):1207-11.

54. Fu YR, Turnell AS, Davis S, Heesom KJ, Evans VC, Matthews DA. Comparison of protein expression during wild-type, and E1B-55k-deletion, adenovirus infection using quantitative time-course proteomics. J Gen Virol. 2017:98(6): 1377-88.

55. Trapnell C, Roberts A, Goff L, Pertea G, Kim D, Kelley DR, Pimentel H, Salzberg SL, Rinn JL, Pachter L. Differential gene and transcript expression analysis of RNA-seq experiments with TopHat and cufflinks. Nat Protoc. 2012;7(3):562-78.

56. Audic S, Claverie JM. The significance of digital gene expression profiles. Genome Res. 1997;7(10):986-95.

57. Tarazona S, Garcia-Alcalde F, Dopazo J, Ferrer A, Conesa A. Differential expression in RNA-seq: a matter of depth. Genome Res. 2011;21(12):2213-23.

58. Huang d W, Sherman BT, Lempicki RA. Systematic and integrative analysis of large gene lists using DAVID bioinformatics resources. Nat Protoc. 2009; 4(1):44-57.

59. Philipson L. Adenovirus assay by the fluorescent cellcounting procedure. Virology. 1961;15:263-8.

60. Shevchenko A, Chernushevich I, Wilm M, Mann M. De novo peptide sequencing by nanoelectrospray tandem mass spectrometry using triple quadrupole and quadrupole/time-of-flight instruments. Methods Mol Biol. 2000;146:1-16

61. Cox J, Matic I, Hilger M, Nagaraj N, Selbach M, Olsen JV, Mann M. A practical guide to the MaxQuant computational platform for SILAC-based quantitative proteomics. Nat Protoc. 2009;4(5):698-705.

62. Zhao H, Dahlo M, Isaksson A, Syvanen AC, Pettersson U. The transcriptome of the adenovirus infected cell. Virology. 2012;424(2):115-28.

63. Kielbasa SM, Klein H, Roider HG, Vingron M, Bluthgen N. TransFind-predicting transcriptional regulators for gene sets. Nucleic Acids Res. 2010; 38(Web Server issue):W275-80

64. Gaboli M, Kotsi PA, Gurrieri C, Cattoretti G, Ronchetti S, Cordon-Cardo C, Broxmeyer HE, Hromas R, Pandolfi PP. Mzf1 controls cell proliferation and tumorigenesis. Genes Dev. 2001;15(13):1625-30.

65. Valdes A, Zhao H, Pettersson U, Lind SB. Time-resolved proteomics of adenovirus infected cells. PLoS One. 2018;13(9):e0204522.

66. Rabinovich GA, Toscano MA. Turning 'sweet' on immunity: galectin-glycan interactions in immune tolerance and inflammation. Nat Rev Immunol. 2009:9(5):338-52.

67. Maier O, Marvin SA, Wodrich H, Campbell EM, Wiethoff CM. Spatiotemporal dynamics of adenovirus membrane rupture and endosomal escape. J Virol. 2012;86(19):10821-8 
68. Trinh HV, Grossmann J, Gehrig P, Roschitzki B, Schlapbach R, Greber UF, Hemmi S. iTRAQ-based and label-free proteomics approaches for studies of human adenovirus infections. Int J Proteomics. 2013;2013:581862.

69. Fejer G, Freudenberg M, Greber UF, Gyory I. Adenovirus-triggered innate signalling pathways. Eur J Microbiol Immunol (Bp). 2011;1(4):279-88.

70. Zhao H, Chen M, Pettersson U. Identification of adenovirus-encoded small RNAs by deep RNA sequencing. Virology. 2013;442(2):148-55.

71. Brockmann $\mathrm{D}$, Esche $\mathrm{H}$. The multifunctional role of E1A in the transcriptional regulation of CREB/CBP-dependent target genes. Curr Top Microbiol Immunol. 2003;272:97-129.

72. Pelka P, Ablack JN, Fonseca GJ, Yousef AF, Mymryk JS. Intrinsic structural disorder in adenovirus E1A: a viral molecular hub linking multiple diverse processes. J Virol. 2008;82(15):7252-63.

73. Romanov VS, Brichkina Al, Morrison H, Pospelova TV, Pospelov VA, Herrlich P. Novel mechanism of JNK pathway activation by adenoviral E1A. Oncotarget. 2014;5(8):2176-86.

74. Zhao H, Granberg F, Elfineh L, Pettersson U, Svensson C. Strategic attack on host cell gene expression during adenovirus infection. J Virol. 2003;77(20): 11006-15.

75. Frisch SM, Mymryk JS. Adenovirus-5 E1A: paradox and paradigm. Nat Rev Mol Cell Biol. 2002;3(6):441-52.

76. Lang SE, Hearing P. The adenovirus E1A oncoprotein recruits the cellular TRRAP/GCN5 histone acetyltransferase complex. Oncogene. 2003;22(18): 2836-41.

77. Kim TK, Maniatis T. Regulation of interferon-gamma-activated STAT1 by the ubiquitin-proteasome pathway. Science. 1996;273(5282):1717-9.

78. Wen Z, Zhong Z, Darnell JE Jr. Maximal activation of transcription by Stat1 and Stat3 requires both tyrosine and serine phosphorylation. Cell. 1995; 82(2):241-50.

79. Kalvakolanu DV, Bandyopadhyay SK, Harter ML, Sen GC. Inhibition of interferon-inducible gene expression by adenovirus E1A proteins: block in transcriptional complex formation. Proc Natl Acad Sci U S A. 1991;88(17): 7459-63.

80. Leonard GT, Sen GC. Effects of adenovirus E1A protein on interferonsignaling. Virology. 1996;224(1):25-33.

81. Frost JR, Mendez M, Soriano AM, Crisostomo L, Olanubi O, Radko S, Pelka P. Adenovirus 5 E1A-mediated suppression of p53 via FUBP1. J Virol. 2018;92(14).

82. Chahal JS, Gallagher C, DeHart CJ, Flint SJ. The repression domain of the E1B 55-kilodalton protein participates in countering interferon-induced inhibition of adenovirus replication. J Virol. 2013;87(8):4432-44.

83. Spurrell E, Gangeswaran R, Wang P, Cao F, Gao D, Feng B, Wold W, Tollefson A, Lemoine NR, Wang Y. STAT1 interaction with E3-14.7K in monocytes affects the efficacy of oncolytic adenovirus. J Virol. 2014;88(4): 2291-300.

84. Sohn SY, Hearing P. Adenovirus sequesters phosphorylated STAT1 at viral replication centers and inhibits STAT dephosphorylation. J Virol. 2011;85(15): 7555-62.

85. Rao L, Debbas M, Sabbatini P, Hockenbery D, Korsmeyer S, White E. The adenovirus E1A proteins induce apoptosis, which is inhibited by the E1B 19kDa and Bcl-2 proteins. Proc Natl Acad Sci U S A. 1992;89(16):7742-6.

86. Shen Y, Shenk T. Relief of p53-mediated transcriptional repression by the adenovirus E1B 19-kDa protein or the cellular BCl-2 protein. Proc Natl Acad Sci U S A. 1994;91(19):8940-4.

87. Somasundaram K, El-Deiry WS. Inhibition of p53-mediated transactivation and cell cycle arrest by E1A through its p300/CBP-interacting region. Oncogene. 1997;14(9):1047-57.

Ready to submit your research? Choose BMC and benefit from:

- fast, convenient online submission

- thorough peer review by experienced researchers in your field

- rapid publication on acceptance

- support for research data, including large and complex data types

- gold Open Access which fosters wider collaboration and increased citations

- maximum visibility for your research: over $100 \mathrm{M}$ website views per year

At BMC, research is always in progress.

Learn more biomedcentral.com/submissions 